\title{
Formation and Evolution of Cu-Sn Intermetallic Compounds in Ultrasonic-Assisted Soldering
}

\author{
WEIYUAN YU, ${ }^{1,2}$ YINGZONG LIU, ${ }^{1}$ and YUN LIU ${ }^{1}$ \\ 1.-State Key Laboratory of Gansu Province, Advanced Processing and Recycling of Nonferrous \\ Metals, Lanzhou University of Technology, Lanzhou 730050, Gansu Province, People's Republic of \\ China. 2.-e-mail: weiyuanyu2018@163.com
}

\begin{abstract}
Interfacial intermetallic compounds (IMCs) help determine the reliability of soldered joints; thus, it is necessary to understand their formation and evolution. This study focus on $\mathrm{Cu}$-Sn IMCs formed in ultrasonic-assisted soldering (UAS), wherein the formation of IMCs at the $\mathrm{Sn} / \mathrm{Cu}$ interface is controlled by changing the ultrasonic action time. After being subjected to ultrasonic vibration, the IMCs at the $\mathrm{Cu} / \mathrm{Sn}$ solid-liquid interface are continuously crushed, dissolved, and formed, which occurs successively in the $\mathrm{Cu}_{6} \mathrm{Sn}_{5}$ and $\mathrm{Cu}_{3} \mathrm{Sn}$ layers. The relationship between the thickness of the IMC layer and ultrasonic action time in $\mathrm{Cu}-\mathrm{Sn}$ samples was identified. Simultaneously, the growth pattern of $\mathrm{Cu}_{6} \mathrm{Sn}_{5}$ grains in the $\mathrm{Sn}$ solder is transformed, and the tin solder (Sn solder) is kept in a dynamic non-equilibrium state with IMCs at the $\mathrm{Sn} / \mathrm{Cu}$ interface through UAS. More $\mathrm{Cu}_{6} \mathrm{Sn}_{5}$ grains formed and were evenly distributed in the joint after cooling, which improves the performance of the joints.
\end{abstract}

Key words: Ultrasonic-assisted soldering, interfacial intermetallic compounds, microstructure, tin solder

\section{INTRODUCTION}

The reliability and thermal fatigue lifetime of solder joints has a major effect on the service life of electronic devices; the interfacial intermetallic compound (IMC) layer of the joints has an especially significant effect on the reliability of soldered joints. $^{1,2}$ The $\mathrm{Cu} / \mathrm{Sn} / \mathrm{Cu}$ system of electronic packaging has been systematically studied in recent decades, showing that $\mathrm{Sn}$ solder reacts with the $\mathrm{Cu}$ substrate to generate $\mathrm{Cu}-\mathrm{Sn}$ IMCs, including $\mathrm{Cu}_{6} \mathrm{Sn}_{5}$ and $\mathrm{Cu}_{3} \mathrm{Sn}^{3-5}$ Excessively thick IMC layers seriously reduce the reliability of soldered joints, or a thinner IMC layer is difficult to ensure connection reliability between the $\mathrm{Cu}$ substrate and $\mathrm{Sn}$ solder. Therefore, the thickness of the IMC layer must be controlled to ensure a better solder joint in the electronic packaging industry.

(Received December 19, 2018; accepted June 26, 2019;

published online July 8, 2019)
Recently, ultrasonic-assisted brazing, a wellknown fluxless brazing method, has been widely studied for soldering in the electronics industry owing to its excellent properties. ${ }^{6-8}$ Previous studies have shown that the propagation of ultrasonic waves in a liquid solder can generate acoustic cavitation and streaming phenomena at the interface, which not only breaks the oxide film on the solid surface, but also improves the wetting of the liquid metal on the solid surface and promotes the diffusion of atoms. ${ }^{9,10}$ Xiao et al. ${ }^{11}$ brazed a $\mathrm{Cu} / \mathrm{Al}$ substrate with $\mathrm{Zn}-3 \mathrm{Al}$ as a brazing filler metal, showing that excellent metallurgic bonding could be obtained in fluxless brazed $\mathrm{Cu} / \mathrm{Al}$ joints by using ultrasonic-assisted soldering (UAS). Li et al. ${ }^{12}$ also found that soldering time could be greatly shortened-and an excellent joint could be obtained-at lower soldering temperatures in the ultrasonicassisted transient liquid phase (TLP) soldering process, which helped avoid extra thermal stress from excessive temperature or longer soldering times on the bond components. All these studies 
indicated that UAS has become the most promising soldering technology for application to electronic component packaging. However, there is little research on the formation and evolution of IMCs or their effects on joint properties when using UAS. Therefore, this study employs the $\mathrm{Cu}$-Sn system to study the formation and evolution of IMCs by UAS. Its results can provide theoretical guidance for the application of UAS in microelectronic packaging.

\section{EXPERIMENTAL PROCEDURES}

Highly pure (99.99 wt.\%) $50 \mathrm{~mm} \times 20 \mathrm{~mm} \times 3$ $\mathrm{mm}$ and $40 \mathrm{~mm} \times 20 \mathrm{~mm} \times 3 \mathrm{~mm} \mathrm{Cu}$ plates were used as substrates, and pure (99.99 wt.\%) $10 \mathrm{~mm} \times$ $15 \mathrm{~mm} \times 0.3 \mathrm{~mm}$ Sn plates were used as the solder. Before performing the brazing experiment, the Sn foils were cleaned with a detergent solution, then rinsed with deionised water, and finally cleaned using acetone in an ultrasonic bath for $3 \mathrm{~min}$. The surfaces of $\mathrm{Cu}$ substrates were first ground and polished. Then they were cleaned using $5 \% \mathrm{HCl}$ in an ultrasonic bath for $3 \mathrm{~min}$ and finally cleaned using acetone, also in an ultrasonic bath for $3 \mathrm{~min}$. Figure 1 shows a schematic of UAS.

The $\mathrm{Cu} / \mathrm{Sn} / \mathrm{Cu}$ structure was placed in a furnace and heated at a rate of $50^{\circ} \mathrm{C} / \mathrm{min}$ up to $300^{\circ} \mathrm{C}$ and then held for $6 \mathrm{~min}$ at $300^{\circ} \mathrm{C}$ during the process of soldering. The horizontal ultrasonic vibration frequency was fixed at $20 \mathrm{kHz}$, a pressure of $0.6 \mathrm{MPa}$, and power of $500 \mathrm{~W}$. After applying ultrasonic waves, samples were derived from the heating platform and quickly cooled in water. The mounted samples were successively ground using \#800, $\# 1000$, \#1500, \#2000, and \#3000 metallographic sandpaper. Finally, the samples were polished mechanically using $0.5 \mu \mathrm{m}$ diamond polishing paste. Subsequently, a few samples were deeply etched in a $5 \% \mathrm{HCl}+3 \% \quad \mathrm{HNO}_{3}+\mathrm{CH}_{3} \mathrm{OH}$ (wt.\%) etchant solution to remove the excess Sn solder so that the formation of interfacial $\mathrm{Cu}_{6} \mathrm{Sn}_{5}$ grains can be investigated during soldering. The microstructures of the joints were examined using backscattered electron signals from an EDS-equipped FEG 450 scanning

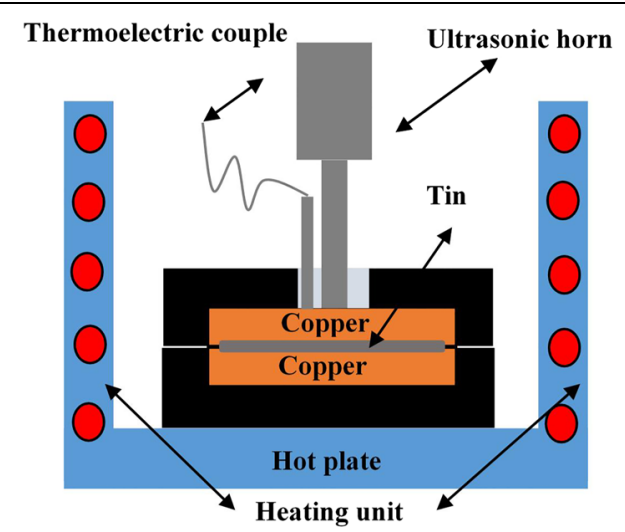

Fig. 1. Schematic of ultrasonic-assisted soldering. electron microscope (SEM), including the distribution of $\mathrm{Cu}$ and $\mathrm{Sn}$ atoms, and the formation and evolution of $\mathrm{Cu}-\mathrm{Sn}$ IMCs by UAS. In addition, the average thickness of the IMC layer in these samples was also determined by counting the total area and length of the IMCs along the interface in the SEM images, and it was calculated using the following equation $^{13}$ :

$$
H=\frac{S}{L}
$$

where $H$ is the average thickness of the IMCs, $S$ is the total IMC area (including $\mathrm{Cu}_{6} \mathrm{Sn}_{5}$ and $\mathrm{Cu}_{3} \mathrm{Sn}$ ), and $L$ is the total length of the interface in the SEM images for one sample.

\section{RESULTS AND DISCUSSION}

\section{The Relationship Between IMC Thickness and Ultrasonic Action Time}

Figure 2 shows the microstructures of the $\mathrm{Cu}-\mathrm{Sn}$ joints formed via UAS at $300^{\circ} \mathrm{C}$ for various ultrasonic action times. Figure 2a shows a morphology photograph of joints soldered for $6 \mathrm{~min}$ without ultrasonic action, where the IMC layer is scallopshaped. As presented in Table I, an EDS analysis revealed that the reaction layer labelled as ' 1 ' is $\mathrm{Cu}_{6} \mathrm{Sn}_{5}$. The dark, thin layer labelled as ' 2 ' is a layer of $\mathrm{Cu}_{3} \mathrm{Sn}$, which is consistent with previous literature. ${ }^{14,15} \mathrm{~A}$ few $\mathrm{Cu}_{6} \mathrm{Sn}_{5}$ particles labelled as ' 3 ' are randomly distributed in the $\mathrm{Sn}$ solder. Figure $2 \mathrm{~b}$ shows a photograph of the morphology of joints after ultrasonic action for $10 \mathrm{~s}$, in which the morphology of the interfacial IMC layers has changed slightly. However, the volume of $\mathrm{Cu}_{6} \mathrm{Sn}_{5}$ in the Sn solder has significantly increased. Figure $2 c$ and $d$ show the microstructure of joints with ultrasonic action time of $20 \mathrm{~s}$ and $30 \mathrm{~s}$, respectively. Note that the volume of $\mathrm{Cu}_{6} \mathrm{Sn}_{5}$ in the Sn solder further increased, and the $\mathrm{Cu}_{6} \mathrm{Sn}_{5}$ layer was crushed after ultrasonic action for $30 \mathrm{~s}$. When the ultrasonic action time was increased to $40 \mathrm{~s}$, the interfacial IMC layer was clearly crushed, as shown in Fig. 2e, the scallopshaped compound layer disappeared, and the $\mathrm{Cu}_{3} \mathrm{Sn}$ layer was also crushed. Simultaneously, the morphology of the compound in the Sn solder transformed from a strip block to a multi-planar layer. ${ }^{16}$ This change in IMC morphology was more evident when ultrasonic vibration was applied for $50 \mathrm{~s}$, as shown in Fig. $2 \mathrm{f}$.

Figure 3 demonstrates SEM images of $\mathrm{Cu}-\mathrm{Sn}$ samples after ultrasonic action for $50 \mathrm{~s}$, in which three broken pits can be observed in the IMC layer. Further analysis revealed that the broken pits labelled as ' 1 ' are only $\mathrm{Cu}_{6} \mathrm{Sn}_{5}$. The broken pits labelled as ' 1 ' are $\mathrm{Cu}_{3} \mathrm{Sn}, \mathrm{Cu}_{6} \mathrm{Sn}_{5}$, and the $\mathrm{Cu}$ substrate, and some $\mathrm{Cu}_{3}$ Sn could also be found in broken pits ' 3 '.

Figure 4 demonstrates the relationship between the thickness of the IMC layer and ultrasonic action 

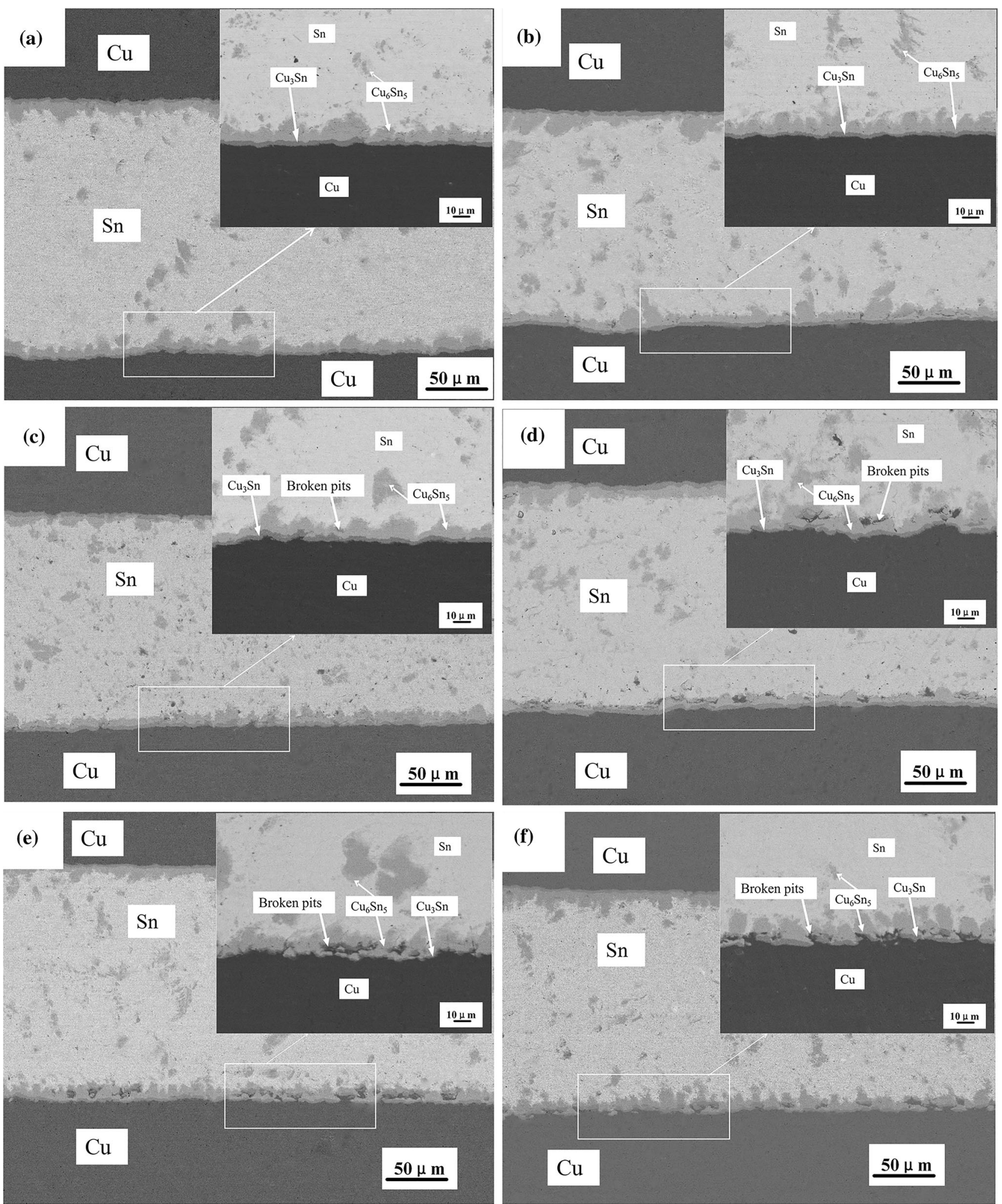

Fig. 2. SEM images of Cu-Sn samples after ultrasonic action for (a) $0 \mathrm{~s}$, (b) $10 \mathrm{~s}$, (c) $20 \mathrm{~s}$, (d) $30 \mathrm{~s}$, (e) $40 \mathrm{~s}$, and (f) $50 \mathrm{~s}$.

time, and the thickness of the total IMC layer and that of the $\mathrm{Cu}_{6} \mathrm{Sn}_{5}$ layer decreased with increasing ultrasonic action time. However, the $\mathrm{Cu}_{3} \mathrm{Sn}$ layer initially increased with ultrasonic action for around $30 \mathrm{~s}$, then decreased after the ultrasonic bonding time increased to $40 \mathrm{~s}$. 
Figure 5 shows the relationship between the IMC in the Sn solder and ultrasonic action time. The distribution area of the $\mathrm{Cu}_{6} \mathrm{Sn}_{5}$ in the $\mathrm{Sn}$ solder was increased with the propagation of ultrasonic waves. Additionally, the interfacial IMC layer was also thinned with increasing ultrasonic action time. Therefore, it could be inferred that the interfacial IMCs were crushed, and their formation was pro-

\section{Table I. Chemical composition at different} locations in Cu-Sn joints in Fig. 2 (at.\%)

\begin{tabular}{lcc}
\hline Location & Cu (at.\%) & Sn (at.\%) \\
1 & 55.6 & 44.4 \\
2 & 72.8 & 27.2 \\
3 & 50.2 & 49.8 \\
\hline
\end{tabular}

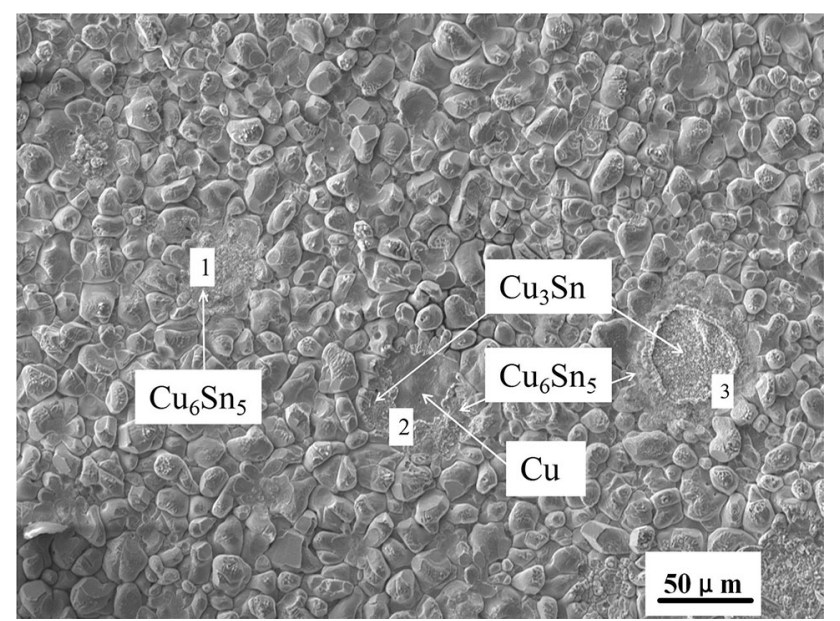

Fig. 3. SEM images of Cu-Sn samples after ultrasonic action for $50 \mathrm{~s}$.

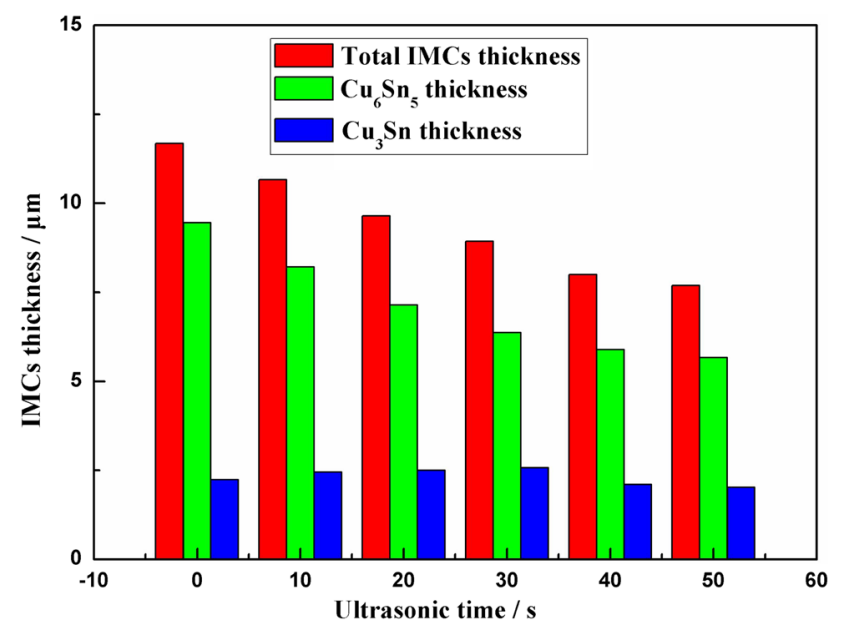

Fig. 4. Relationship between the thickness of the IMC layer and ultrasonic action time in Cu-Sn samples. moted by ultrasonic action.

The translation of $\mathrm{Cu}_{6} \mathrm{Sn}_{5}$ in $\mathrm{Sn}$ solder is given in the following equation:

$$
Y=A X^{2}+B X+C
$$

where $Y$ is the area of $\mathrm{Cu}_{6} \mathrm{Sn}_{5}$ in the Sn solder, and $X$ is ultrasonic action time. The values of $\mathrm{A}, \mathrm{B}$, and $\mathrm{C}$ were found from the fitting to be as -0.26916 ( \pm 0.07908), $36.75435( \pm 4.25974)$, and 2140.50186 ( \pm 44.32127), respectively.

If the shape of $\mathrm{Cu}_{6} \mathrm{Sn}_{5}$ in $\mathrm{Sn}$ solder is considered to be a circle, where the radius, i.e. the equivalent circular radius, can be obtained by Eq. 3, $R$ is the equivalent circular radius of the $\mathrm{Cu}_{6} \mathrm{Sn}_{5}$ in the $\mathrm{Sn}$ solder. According to this analysis, $Z$ is linear with $X$, as shown in Fig. 5b. That is, the formation of $\mathrm{Cu}_{6} \mathrm{Sn}_{5}$ in the $\mathrm{Sn}$ solder was mainly controlled by the reaction in Eq. $4 .^{17}$

$$
\begin{gathered}
R=\sqrt{\frac{Y}{\pi}} \\
R=D X+E
\end{gathered}
$$

where $X$ is the ultrasonic action time, and $D$ and $E$ were found from the fitting to be 0.11189 $( \pm 0.00851) \quad$ and $=27.11665 \quad( \pm 0.28593)$, respectively.

The above analysis found that the application of ultrasonic waves not only promotes the diffusion of $\mathrm{Cu}$ atoms, but also accelerates the growth of compounds in the Sn solder. Previous studies have shown that propagation of ultrasonic waves in a liquid medium can generate acoustic cavitation phenomena, ${ }^{18}$ in which numerous micro-bubbles are generated and grow significantly. When these bubbles approach the solid-liquid interface, they rapidly implode because their movement is hampered, which can induce a localised high-temperature, high-pressure environment and micro-jet phenomena at the $\mathrm{Cu} / \mathrm{Sn}$ solid-liquid interface. ${ }^{19}$ Simultaneously, the exploding bubbles can form a powerful shock wave, ${ }^{20}$ which accelerates the turbulent flow of the liquid. The high-speed fluid would constantly flush the surface of the base metal and the previously formed IMC layer. As shown in Fig. 2c and $d$, the pre-formed IMC layer at the interface was constantly crushed by the shock waves and cavitation bubbles, which led the scallop-like IMC layer to disappear and a few crushed pits to form at the $\mathrm{Cu} / \mathrm{Sn}$ solid-liquid interface. For ultrasonic action time up to $40 \mathrm{~s}$, the broken pits appeared in the $\mathrm{Sn} / \mathrm{Cu}_{6} \mathrm{Sn}_{5}$ and $\mathrm{Cu}_{3} \mathrm{Sn} / \mathrm{Cu}_{6} \mathrm{Sn}_{5}$ interfaces, as shown in Fig. 2e. The same phenomenon could be observed after ultrasonic action for $50 \mathrm{~s}$, as shown in Fig. 2f. In addition, the preformed IMC layer in the solid-liquid interface could obstruct the diffusion of $\mathrm{Cu}$ atoms into the $\mathrm{Sn}$ solder at ultrasonic action times of around $30 \mathrm{~s}$, which causes a few of the $\mathrm{Cu}$ atoms to diffuse from the base 

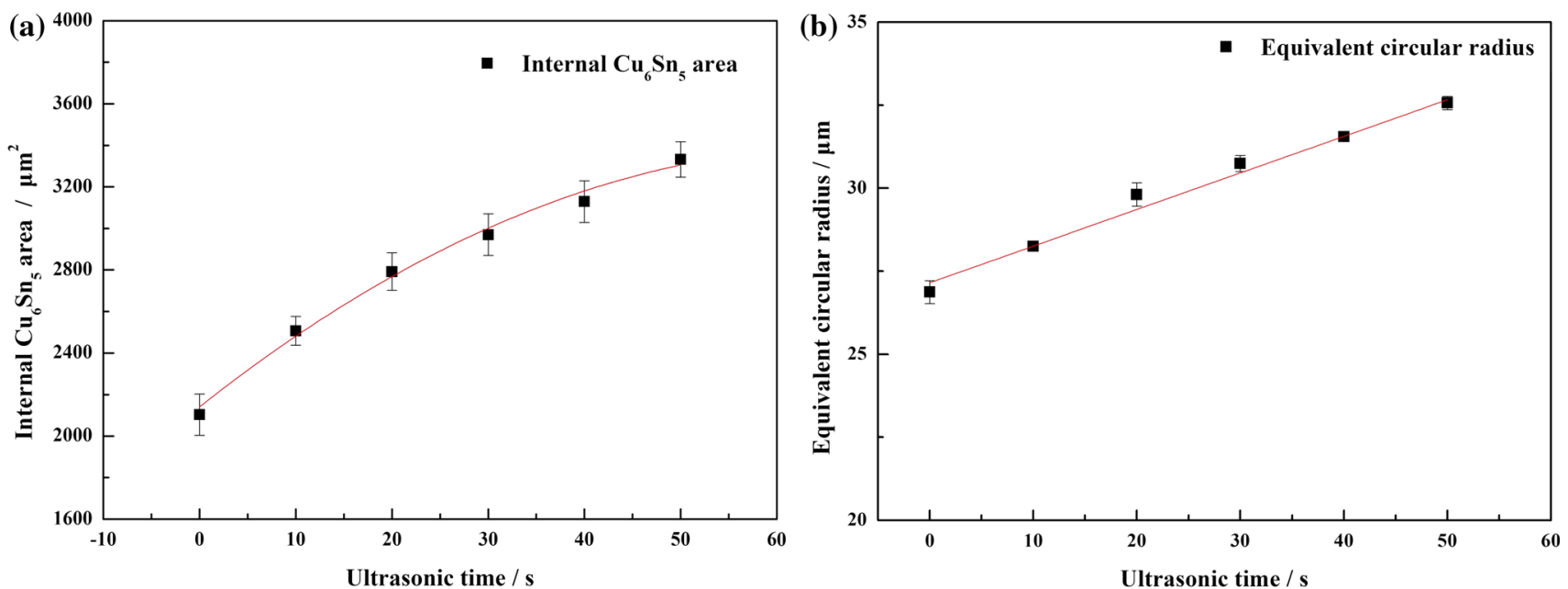

Fig. 5. (a) Area of $\mathrm{Cu}_{6} \mathrm{Sn}_{5}$ in the $\mathrm{Sn}$ solder and (b) An equivalent circular radius of $\mathrm{Cu}_{6} \mathrm{Sn}_{5}$ in $\mathrm{Sn}$ solder as functions of the ultrasonic action time.

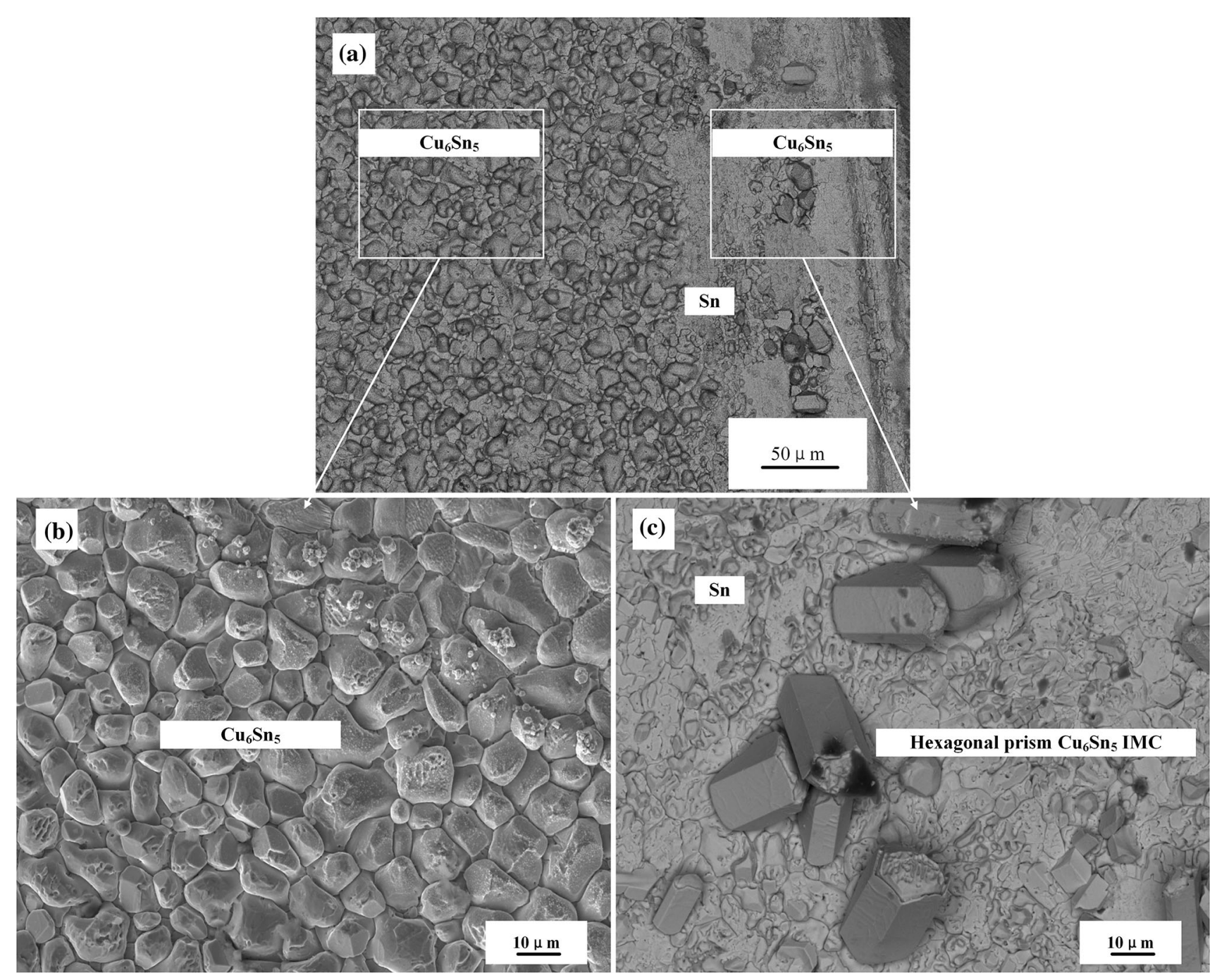

Fig. 6. Morphology of Cu-Sn samples with IMCs in the joint (a), at the interface (b), and in the Sn solder (c) after bonding for 6 min at $300^{\circ} \mathrm{C}$. 

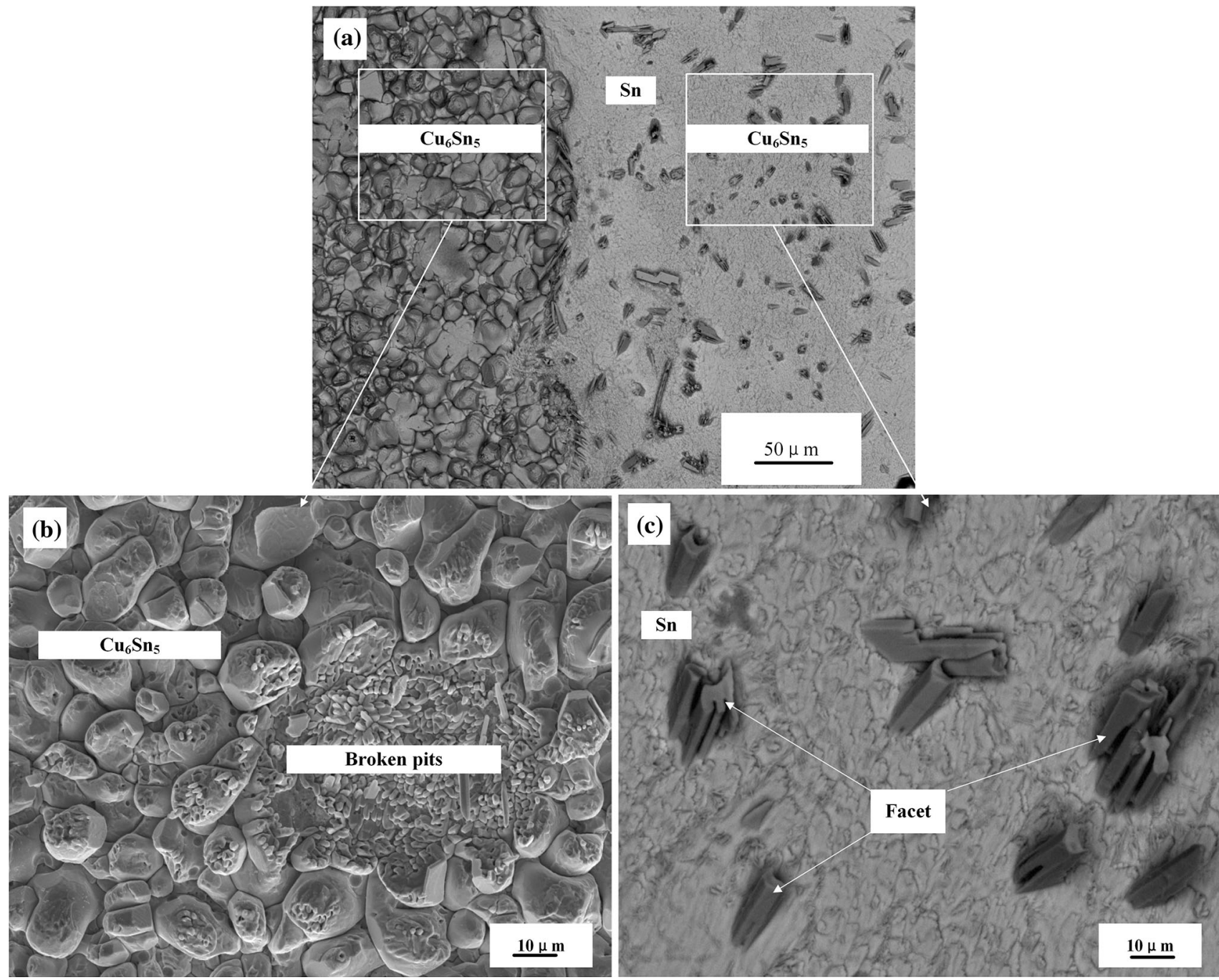

Fig. 7. Morphology of Cu-Sn IMCs in the joint (a), at the interface (b), and in the Sn solder (c) after ultrasonic action for $40 \mathrm{~s}$.

metal to accumulate at the $\mathrm{Cu}_{3} \mathrm{Sn} / \mathrm{Cu}_{6} \mathrm{Sn}_{5}$ interface. Meanwhile, shock waves, cavitation bubbles, and localised high temperatures led to micro-damages of the solid $\mathrm{Cu}$ surface, which produced an excessive number of $\mathrm{Cu}$ atoms detached from the $\mathrm{Cu}$ surface and spread into the molten Sn solder. The additional $\mathrm{Cu}$ atoms provide excellent conditions for the formation of $\mathrm{Cu}_{3} \mathrm{Sn}$. Note that the average thickness of the $\mathrm{Cu}_{3} \mathrm{Sn}$ layer slowly increased during ultrasonic action times in the range of $30 \mathrm{~s}$, as shown in Fig. 4. However, when the ultrasonic action time increased to $40 \mathrm{~s}$, the average thickness of the $\mathrm{Cu}_{3} \mathrm{Sn}$ layer began to decrease, which was attributed to the crushing of the IMC layer. The crushed IMC layer could provide a few new diffusion channels for $\mathrm{Cu}$ and $\mathrm{Sn}$ atoms, which makes it easier for the $\mathrm{Cu}$ atoms to dissolve away from the base metal to diffuse into the Sn solder under the effect of chemical gradients and acoustic flow. $\mathrm{Cu}_{6} \mathrm{Sn}_{5}$ generated in the Sn solder with ultrasonic action times of $40 \mathrm{~s}$ and $50 \mathrm{~s}$, shown in Fig. $2 \mathrm{e}$ and $\mathrm{f}$, differed from its generation in the Sn solder with ultrasonic action times of approximately $30 \mathrm{~s}$.

\section{Morphology of Interfacial IMCs by UAS}

As shown in Figs. 6 and 7, the joints were pulled away in two parts from the bonding surface, one of which was ground layer by layer until the IMC layer was observed by SEM. Figure 6 shows the grain morphology of $\mathrm{Cu}_{6} \mathrm{Sn}_{5}$ without ultrasonic action. The $\mathrm{Cu}_{6} \mathrm{Sn}_{5}$ grains at the $\mathrm{Sn} / \mathrm{Cu}$ interface were mainly scallop-shaped, as shown in Fig. 6b, whereas the $\mathrm{Cu}_{6} \mathrm{Sn}_{5}$ grains generated in the Sn solder were regular hexagonal prisms, as shown in Fig. 6c. Figure 7 illustrates the grain morphology of $\mathrm{Cu}_{6} \mathrm{Sn}_{5}$ with ultrasonic action for $40 \mathrm{~s}$. Although the grain morphology of $\mathrm{Cu}_{6} \mathrm{Sn}_{5}$ at the $\mathrm{Sn} / \mathrm{Cu}$ interface was still scallop-like in shape, a few obviously broken pits in the interfacial $\mathrm{Cu}_{6} \mathrm{Sn}_{5}$ layer could be found. 
Simultaneously, the grain morphology of $\mathrm{Cu}_{6} \mathrm{Sn}_{5}$ in the Sn solder was in the facet-shaped instead of a regular hexagonal prism, meaning that the ultrasonic action could cause the interfacial IMC layer to be crushed and the growth pattern of $\mathrm{Cu}_{6} \mathrm{Sn}_{5}$ grains in the Sn solder to be transformed.

According to Jackson, ${ }^{21}$ atomic geometry-including facet- or round-shaped geometry-is mainly determined by the Jackson's coefficient of the crystal. Choi et al. ${ }^{22}$ extended Jackson's theory to the grain morphology of the IMC that forms at the interface between liquid solder and solid-metal substrates. The morphology of IMCs was also found to be related to Jackson's coefficient. That is, Jackson's coefficient of a round grain is always less than 2, but Jackson's coefficient for a faceted grain is greater than 2 . Jackson's coefficient depends largely on enthalpy changes, its value is modified as follows:

$$
\alpha=\frac{\Delta H}{R T} \xi
$$

where $\alpha$ is Jackson's coefficient, $\Delta H$ is the enthalpy change during the reaction of the liquid solder and the metal substrate into an IMC, $R$ is a gas constant, $T$ is the soldering temperature, and $\zeta$ is an atomic fraction of possible sites occupied by solid atoms at the growing interface. Because it is difficult to calculate the exact value of $\zeta$-owing to the random orientation between adjacent IMC grains-a mean value of $\zeta=0.5$ can be found in close-packed planes (0001) of hexagonal $\mathrm{Cu}_{6} \mathrm{Sn}_{5}$ was used to find out the different growth patterns of $\mathrm{Cu}_{6} \mathrm{Sn}_{5}$ grains. According to Kirchhoff's law, enthalpy changes are related to the reaction temperature using the following equation:

$$
\Delta H=A_{0}+A_{1} T+A_{2} T^{2}
$$

Yang et al. ${ }^{23}$ showed that the values of $A, A_{0}$, and $A_{1}$ in a pure $\mathrm{Sn} / \mathrm{Cu}$ system are $19064.81,-75.08$, and 0.11 respectively. Thus, a value of $\alpha=1.28$ can be calculated by Eq. 5 at $300^{\circ} \mathrm{C}$. This value is less than 2 , showing that round $\mathrm{Cu}_{6} \mathrm{Sn}_{5}$ grains grow while holding at $300^{\circ} \mathrm{C}$, which is consistent with the behaviour seen in the experiment shown in Fig. 6a. Meanwhile, $\mathrm{Cu}_{6} \mathrm{Sn}_{5}$ formed in the $\mathrm{Sn}$ solder when a few of the $\mathrm{Cu}$ atoms diffused into liquid Sn. Since the $\mathrm{Cu}_{6} \mathrm{Sn}_{5}$ grains had a close-packed hexagonal structure, they grew in hexagonal prisms along the screw dislocations by means of a step mechanism and extended into the Sn solder, as shown in Fig. 6c. However, when ultrasonic vibration was applied, the cavitation bubbles rapidly collapsed, which creates hot spots with the localised temperature and pressure estimated to reach $5000 \mathrm{~K}$ and $0.1 \mathrm{GPa}$, respectively. The liquid near the cavitation bubble is also affected, and its effective temperature can reach $1600^{\circ} \mathrm{C} .^{24}$ The enthalpy change in the entire joint increased owing to the high-temperature, high-pressure environment. Substituting the effective temperature into Eq. 5, Jackson's coefficient was calculated as 8.49-considerably greater than 2-meaning that the $\mathrm{Cu}_{6} \mathrm{Sn}_{5}$ grains grow in a facet-shaped geometry under ultrasonic action. Furthermore, $\mathrm{Cu}$ and $\mathrm{Sn}$ atoms continuously underwent interdiffusion, driven by the temperature and concentration gradients before applying ultrasonic action, but the speed of diffusion was relatively slow. Thus, the $\mathrm{Cu}$ atoms that diffused into $\mathrm{Sn}$ solder gathered at the $\mathrm{Cu} / \mathrm{Sn}$ solid-liquid interface. However, when ultrasonic waves were applied, the action of ultrasonic waves caused the liquid Sn to continuously flow at a high speed. This instantaneously brought the $\mathrm{Cu}$ and $\mathrm{Sn}$ atoms into the liquid Sn under the action of the acoustic current, resulting in a new concentration gradient at the $\mathrm{Cu} / \mathrm{Sn}$ solid-liquid interface, which accelerated the dissolution rate of base metals into the liquid solder. The effect of the ultrasonic waves made it difficult for $\mathrm{Cu}$ atoms to gather inside the Sn solder. To reduce the nucleation energy, precipitation usually took place at the existing IMC interface, as the liquid solder would otherwise be supersaturated. Therefore, the growth of $\mathrm{Cu}_{6} \mathrm{Sn}_{5}$ grains was considerably enhanced, and the dissolution of $\mathrm{Cu}$ atoms was considerably improved, leading to a facet-shaped geometry, as shown in Fig. 7.

In addition, the application of ultrasonic waves can induce intense acoustic streaming in liquids, which accelerate the dissolution rate of base metals into the liquid solder by promoting elemental diffusion in the liquid solder at high speed. Therefore, the Sn solder was in a dynamic non-equilibrium state such that IMCs at the $\mathrm{Cu} / \mathrm{Sn}$ solid-liquid interface were crushed continuously, dissolved, and formed by UAS. Some crushed $\mathrm{Cu}_{6} \mathrm{Sn}_{5}$ enters the $\mathrm{Sn}$ solder, and others dissolve at the local high temperatures. The dissolved $\mathrm{Cu}$ and $\mathrm{Sn}$ atoms provided conditions for the growth of $\mathrm{Cu}_{6} \mathrm{Sn}_{5}$. Meanwhile, ultrasonic vibration and agitation relied on external input energy, promoted the formation of internal $\mathrm{Cu}_{6} \mathrm{Sn}_{5}$ crystal nuclei, and fractured the growing dendrites. More $\mathrm{Cu}_{6} \mathrm{Sn}_{5}$ grains formed and were evenly distributed in the joint after cooling, which would improve the performance of welded joints. ${ }^{25,26}$

\section{CONCLUSIONS}

The effects of UAS on the microstructure of $\mathrm{Cu}-\mathrm{Sn}$ IMCs were investigated, and the major conclusions can be summarised as follows:

1. When ultrasonic waves were introduced to the soldering joint, the IMC dendrites generated at the $\mathrm{Cu} / \mathrm{Sn}$ solid-liquid interface broke, which led to a severe decrease in the thickness of the $\mathrm{Cu}_{6} \mathrm{Sn}_{5}$ and $\mathrm{Cu}_{3} \mathrm{Sn}$ layers.

2. The ultrasonic vibration and agitation promoted the nucleation of $\mathrm{Cu}_{6} \mathrm{Sn}_{5}$ crystals in the $\mathrm{Sn}$ solder, which was kept in a dynamic nonequilibrium state with IMCs at the $\mathrm{Sn} / \mathrm{Cu}$ interface and in the Sn solder. 
3. With the propagation of ultrasonic waves, the enthalpy of the $\mathrm{Cu}-\mathrm{Sn}$ system increased, and $\mathrm{Cu}_{6} \mathrm{Sn}_{5}$ grains in the $\mathrm{Sn}$ solder grew into facet shapes instead of round shapes.

\section{ACKNOWLEDGMENTS}

This work was supported financially by the National Natural Science Foundation of China (Nos. 51465032 and 51665031).

\section{REFERENCES}

1. X. Ma, Y. Qian, and F. Yoshida, J. Alloys Compd. 334, 224 (2002).

2. Y. Zhou, F. Liu, and H. Wang, Polym. Compos. 38, 803 (2017).

3. C. Hang, Y. Tian, R. Zhang, and D. Yang, J. Mater. Sci. Mater. Electron. 24, 3905 (2013).

4. N.S. Bosco and F.W. Zok, Acta Mater. 52, 2965 (2004).

5. T. Laurila, V. Vuorinen, and M. Paulasto-Kröckel, Mater. Sci. Eng. R Rep. 68, 1 (2010).

6. T.H. Kim, J. Yum, S.J. Hu, J.P. Spicer, and J.A. Abell, CIRP Ann. 60, 17 (2011).

7. A. Panteli, J.D. Robson, I. Brough, and P.B. Prangnell, Mater. Sci. Eng. A 556, 31 (2012).

8. W. Guo, T. Luan, X. Leng, J. He, and J. Yan, Trans. Nonferrous Met. Soc. China 27, 962 (2017).

9. K.M. Hafez, M.H. El-Sayed, and M. Naka, Sci. Technol. Weld. Joining 10, 125 (2013).

10. W. Cui, C. Wang, J. Yan, Z. Wang, and D. Wei, Ultrason. Sonochem. 20, 196 (2013).
11. Y. Xiao, H. Ji, M. Li, and J. Kim, Mater. Des. 52, 740 (2013),

12. M. Li, Z. Li, Y. Xiao, and C. Wang, Appl. Phys. Lett. 102, 094104 (2013).

13. B.-H. Kwak, M.-H. Jeong, J.-W. Kim, B. Lee, H.-J. Lee, and Y.-B. Park, Microelectron. Eng. 89, 65 (2012).

14. J.F. Li, P.A. Agyakwa, and C.M. Johnson, Acta Mater. 59, 1198 (2011)

15. H. Liu, K. Wang, K.E. Aasmundtveit, and N. Hoivik, J. Electron. Mater. 41, 2453 (2012).

16. M.S. Park, S.L. Gibbons, and R. Arróyave, Microelectron. Reliab. 54, 1401 (2014).

17. B.-J. Kim, G.-T. Lim, J. Kim, K. Lee, Y.-B. Park, H.-Y. Lee, and Y.-C. Joo, J. Electron. Mater. 39, 2281 (2010).

18. K.S. Suslick, Sci. Am. 260, 80 (1989).

19. S.D. Hyman, T.J. Lazio, N.E. Kassim, P.S. Ray, C.B. Markwardt, and F. Yusef-Zadeh, Nature 434, 50 (2005).

20. E.A. Brujan, T. Ikeda, and Y. Matsumoto, Exp. Therm. Fluid Sci. 32, 1188 (2008).

21. K.A. Jackson, Prog. Solid State Chem. 4, 53 (1967).

22. W.K. Choi, S.-Y. Jang, J.H. Kim, K.-W. Paik, and H.M. Lee, J. Mater. Res. 17, 597 (2011).

23. M. Yang, M. Li, and C. Wang, Intermetallics 25, 86 (2012).

24. K.S. Suslick, D.A. Hammerton, and R.E. Cline, J. Am. Chem. Soc. 89 (1986).

25. X. Leng, C. Wang, Y. Zhang, X. Chen, and J. Yan, Trans. Nonferrous Met. Soc. China 21, s290 (2011).

26. T. Luan, W. Guo, S. Yang, Z. Ma, J. He, and J. Yan, J. Mater. Process. Technol. 248, 123 (2017).

Publisher's Note Springer Nature remains neutral with regard to jurisdictional claims in published maps and institutional affiliations. 